\title{
CONCERNING REQUIREMENTS TO IMPACT TOUGHNESS OF JOINTS OF PIPELINES PRODUCED USING FLASH BUTT WELDING
}

\author{
V.I. KYRIAN, S.I. KUCHUK-YATSENKO and B.I. KAZYMOV \\ E.O. Paton Electric Welding Institute, NASU \\ 11 Bozhenko Str., 03680, Kiev, Ukraine. E-mail: office@paton.kiev.ua
}

\begin{abstract}
To provide serviceability of joints of pipelines produced using flash butt welding (FBW) alongside with the condition of strength the requirement to impact toughness $K C V$ is set forth. Its level is established according to the requirements to the joints produced using arc welding methods, for which the probability of appearance of crack-like defects in them is peculiar. Absence of even preconditions to formation of cracks in the FB-welded joints allows initiating the review of requirements to impact toughness. As the standard level the $K C V$ value is offered, which is reliably provided at optimum mode of FBW performance. The sufficiency of such $K C V$ level is proved by reliable many-years practice in operation of different-purpose pipelines without fractures, including main pipelines of large diameter (up to $1420 \mathrm{~mm}$ ). For the given $K C V$ value at the working circumferential stresses in the pipeline and axial ones equal to half of their value, the critical sizes of hypothetic through longitudinal and circumferential cracks are calculated. Their sufficient sizes prove in appropriateness of such approach. 20 Ref., 3 Figures.
\end{abstract}

Keywords : flash butt welding, typical defects of $F B W$, impact toughness, requirements, critical sizes of hypothetic cracks

The main condition for serviceability of welded joints is the assurance of their strength, which is confirmed by the results of tensile tests of standard smooth (without stress concentrator) specimens, when fracture stress $\sigma_{\mathrm{f}}$ reaches ultimate strength $\sigma_{\mathrm{t}}$ :

$$
\sigma_{\mathrm{f}}=\sigma_{\mathrm{t}} .
$$

Except of condition (1) it is necessary also to guarantee the specified margin of toughness of metal to prevent fractures connected with possible formation of defects and fractures in welded joints. The required fracture toughness of metal depends on the type and size of a defect. The principal significance belongs to the sharpness of concentrator. If a defect is close to a crack-like one, then to eliminate cracking it is most perspective to use criteria of fracture mechanics, which reflect the ability of metal with a crack to plastic deformation without fracture initiating. Thus, the fracture mechanics allows reasonably evaluate the required level of fracture toughness, providing the serviceability of welded joints with crack-like defects of a certain size.

At the present time to establish the requirements to fracture toughness, the impact toughness $K C V$ is used determined on the standard specimens with sharp notch, the radius of top of which is equal to $0.25 \mathrm{~mm}$. This method found wide practical application due to the fact that quality relation between $K C V$ value and character of fracture of ship-building steel (initiation of crack, its development and arresting) was established [1].

Later in the former USSR the requirements to pipe steels according to $K C V$ values were introduced, which resulted in considerable reduction of fractures of pipelines manufactured of the best for that time low-alloyed steel $17 \mathrm{G} 1 \mathrm{~S}$ and its modifications [2]. Here, to provide the necessary level of impact toughness of metal of pipes of large diameter $(>620 \mathrm{~mm})$ the transition to the new technology of manufacture of metal, i.e. controllable rolling, which obtained its large development abroad [3, 4], was required. And finally with the progress of fracture mechanics [5, 6] the impact toughness obtained some theoretical grounds for formation of requirements to the steel and welded joints according to $K C V$ value with the purpose of elimination of fractures connected with crack-like defects.

From the given examples of use of impact toughness in practice it becomes obvious that the acceptable evaluation of toughness of metal fracture, suitable for prediction of serviceability of welded joints, can be obtained at the condition of proper grounds (theoretical, experimental or practical experience of service). However, today the impact toughness became so customary in practice that it started to be used without correcting of $K C V$ values depending on the applied 
technology of pipe welding and type of occurring defects. Moreover, the $K C V$ values are used, established for electric arc methods of welding, for which the probability of formation of crack-like defects is high. It relates also for high-efficient automatic flash butt welding (FBW). At the same time, as was noted [7,8], in the joints, made by FBW, there is no physical preconditions to formation of crack-like defects due to their formation without molten metal forced out from the fusion zone during upsetting. It is proved by non-destructive testing methods of welded joints (X-ray, ultrasonic) [9, 10] allowing detecting cracks with a high probability and also comprehensive investigations of quality of joints produced using FBW and reliable many-year practice of operation of great number of pipelines, including also those of a large diameter $(1420 \mathrm{~mm})$ [11].

It is a very important and principal moment, which allows putting a task for review of the requirements to impact toughness of joints produced by FBW. Moreover, today the requirements for arc-welded joints are used, for which cracks are the sufficiently obvious defect. These requirements without grounds are transferred to the joints produced by FBW.

The typical «defects» in the joining zone (JZ) in FBW at optimal modes, which were established experimentally according to the conditions of providing strength of joints and absence of inadmissible defects (decreasing strength by more than $5 \%$ ), are the zones of area of about $30 \mathrm{~mm}^{2}$ with increased content of non-metallic inclusions similar by their composition to nonmetallic inclusions of the similar zones in the metal of pipes being its heritage in fact (Figure 1) [12]. They are namely classified as the local structural heterogeneity (LSH).

The aim of this work is investigation of influence of LSH in welded joints of pipes on their mechanical properties and selection of grounded principle of formation of requirements to impact toughness of joints produced using FBW, which do not contain cracks.

Evaluation of mechanical properties of welded joints was carried out on a great number of fullscale pipes of 920-1420 mm diameter with wall thickness of $15.7-27 \mathrm{~mm}$ thickness of X60-X70 class of strength, produced at the optimal modes under the conditions of industrial production during construction of main pipelines and also at the testing area of the E.O. Paton Electric Welding Institute. For this purpose, the sections of plates of low-carbon low-alloyed pipe steels of modern production of up to $27 \mathrm{~mm}$ thickness

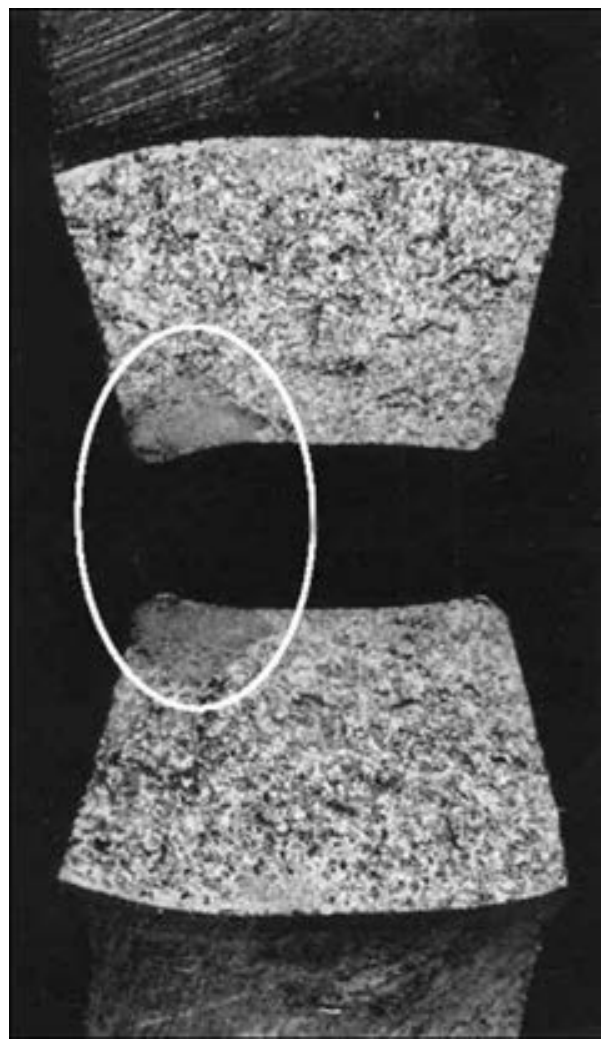

Figure 1. Fracture surface of specimen of joint, made by FBW, with LSH (marked in oval) tested for impact bending

of different classes of strength, including X80, were welded under the laboratory conditions.

The mechanical tests for rupture and impact bending, to which more than 60 butts of different pipes in the as-welded state were subjected, were carried out on standard specimens of welded joints in accordance with the requirements of API 1104 (USA) [13] and SP 105-34-96 (RF) [14].
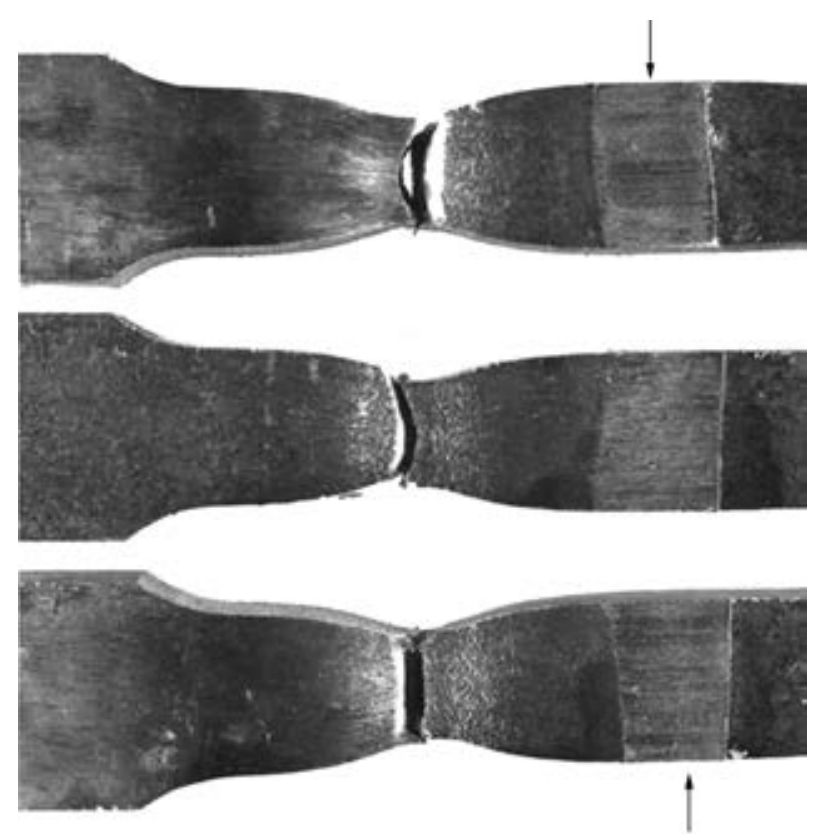

Figure 2. Standard specimens tested for tension. All fractures occurred across the base metal. JZ is shown by arrows 
All the specimens, tested for rupture, were fractured across the base metal (Figure 2). The values of their strength, in spite of a high probability of presence of separate LSH areas in JZ, met the condition of strength (1). It was proved also by the results of tests of large-scale sectors of $300-500 \mathrm{~mm}$ elongation along the welded joint, cut out of pipes of large diameter with the specially produced areas, similar to LSH, in JZ of $10-70 \mathrm{~mm}^{2}$ area [15]. The testing of large-scale sectors of pipes with such defects was carried out both at room temperature and also at $-60{ }^{\circ} \mathrm{C}$.

It was established that the test results on strength do not depend on structural heterogeneity of metal of pipes being welded, as a result of which LSH areas appear in the joints. For example, the joints of pipes with clearly expressed banding of metal, not less than 5 scale numbers (according to GOST 5640-68), i.e. the joints with the highest probability of formation of LSH areas in JZ showed the results meeting condition (1) as well as the joints of pipes, the metal of which had a lower banding (3-4 scale numbers).

The absence of influence of LSH on strength of joints, made by FBW, can be predetermined by the following. LSH does not create local critical stresses, which could lower the fracture stresses [16]. Besides, narrow JZ in FBW is ductile, it has the lowered strength as compared to the surrounding metal, however, it is located between the massive areas of heat-hardened metal. In loading due to contact hardening the mechanical properties of $\mathrm{JZ}$ are increased to the level of neighboring areas, which results in restricting the growth of deformations and manifesting of $\mathrm{LSH}$. It should be also taken into account that probability of manifesting of LSH area in welded joint depends not only on properties of this single area, but also on neighboring ones [17]. It can be reflected by double integral from the function of stresses $\sigma(x, y)$ of two variables, spread to the area $S$ of JZ with LSH:

$$
\iint_{S} \sigma(x, y) d s
$$

where $d s$ is the element of area; $S$ is the area of integration. It represents the averaged total force $F$ in $\mathrm{JZ}$ over the area of integration:

$$
F=\sum_{n=1}^{N} \sigma\left(x_{i}, y_{i}\right) d s_{i} .
$$

For convenience of practical application, formula (2) can be presented in Cartesian coordinates:

$$
\iint_{S} \sigma(x, y) d x d y
$$

where $d x d y$ is the element of area.

Dependence (4) can be expressed in the form of repeated integrals:

$$
\int_{a}^{b} d x \int_{c}^{d} \sigma(x, y) d y
$$

where $a-b$ and $c-d$ are the boundaries of integration, respectively along and across $\mathrm{JZ}$.

The given data and the earlier performed investigations $[8,18]$ show that today requirements to impact toughness of joints, produced by FBW, are groundlessly overstated and need correcting. As far as in these welded joints the cracks are absent, then as the basis of the requirements to them the level of impact toughness should be taken, which is stably provided in FBW performed at optimum mode. The average $K C V$ value of joints produced using FBW which are not subjected to heat treatment is equal to $20 \mathrm{~J} / \mathrm{cm}^{2}$ at testing temperature of $20{ }^{\circ} \mathrm{C}$.

To prove the sufficiency of such $K C V$ level, let us evaluate the critical sizes of hypothetical cracks (longitudinal and circumferential) in the pipeline of $\varnothing 1420 \times 15.7 \mathrm{~mm}$. For this purpose let us use the generalized correlation dependence between impact toughness $K C V$ and critical values of stress intensity factor $K_{1 c}$ established in work [6]. This dependence based on the results of tests of great number of welded joints and steels of different classes with the yield strength of 200-1700 MPa and has the following form:

$$
K_{1 c}=\sqrt{\frac{\pi E K C V}{20 \cdot 10^{2}\left(1-v^{2}\right)}},
$$

where $E$ is the elasticity modulus, $\mathrm{MPa}$; $v$ is the Poisson coefficient; $K C V$ is the impact toughness determined on the standard specimen with a sharp notch (Charpy), $\mathrm{J} / \mathrm{cm}^{2}$.

The results of $K_{1 c}$ calculations (formula(6)) according to $K C V$ values for pipe steels and their welded joints are given in Figure 3.

The formula for determination of critical size of hypothetic through longitudinal crack of $2 l$ length in the closed cylindrical shell depending on fracture toughness of metal $K_{1 c}$, circumferential stress $\sigma_{\theta}$ determined by inner pressure $P$, pipe radius $R$ and thickness of its wall $l\left(\sigma_{\theta}=\right.$ $=P R / t$ ), can be written as follows [19]:

$$
K_{1 c}=\sigma_{\theta} \sqrt{\pi} \bar{l} f_{\text {th.l }}(\xi) \text {. }
$$

The function $f_{\text {th.l }}(\xi)$ is plotted in the form of a series by degrees of parameter $\xi=l^{2} / R t$ on 
the basis of numerical solution of elastic problem for the pipe with the through longitudinal crack according to the general moment theory and is represented in the separate areas with the error of not more than $1 \%$ in the wide range of change of parameter $\xi(0-2812.5)$. At $0<\xi \leq 4.5$

$$
\begin{gathered}
f_{\text {th.l }}(\xi)=1.005672+0.646787 \xi- \\
-0.12454 \xi^{2}+0.12521 \cdot 10^{-1} \xi^{3},
\end{gathered}
$$

and at $4.5 \leq \xi \leq 55.125$

$$
\begin{gathered}
f_{\text {th.l }}(\xi)=1.669865+0.208892 \xi- \\
-0.383589 \cdot 10^{-2} \xi^{2}+0.31666 \cdot 10^{-4} \xi^{3} .
\end{gathered}
$$

According to formula (7) the critical size of hypothetic through longitudinal crack in the pipeline of $1420 \mathrm{~mm}$ diameter with the wall thickness of $15.7 \mathrm{~mm}$ at circumferential stress in the pipe wall determined by the inner pressure $\sigma_{\theta}=$ $=316 \mathrm{MPa}$ which amounts to $0.7 \sigma_{\mathrm{y}}$ and fracture toughness $K_{1 c}=84.6 \mathrm{MPa} \sqrt{\mathrm{m}}$, established according to $K C V=20 \mathrm{~J} / \mathrm{cm}^{2}$ (formula (6)) (see Figure 3 ), is equal to $42.84 \mathrm{~mm}$.

In the underground pipelines alongside with the main circumferential stress $\sigma_{\theta}$ the axial stresses $\sigma_{z}$ also arise, which are not subjected to accurate calculation. They can be both tensile as well as compressive ones $[2,20]$. In this case a great significance belongs to the temperature conditions of closing the main pipeline (welding of the last circumferential butt). Besides, the axial stresses $\sigma_{z}$ are significantly influenced by the properties of soil, determining the level of jamming of pipeline, and also the presence of preweights, compensators and devices of water cooling. Therefore, for evaluation of critical size of hypothetic through circumferential crack in the circumferential butt, made by FBW, we supposed that $\sigma_{z}=0.5 \sigma_{\theta}$.

The limited state of pipeline with such a crack is expressed as follows [19]:

$$
K_{1 c}=\sigma_{z} \sqrt{\pi} l f_{\text {th.c }}(\xi) \text {. }
$$

The function $f_{\text {th.c }}(\xi)$ was numerically determined similarly to $f_{\text {th.l }}(\xi)(7)$. Thus, at $0<\xi \leq$ $\leq 7.71$

$$
\begin{aligned}
& f_{\text {th.c }}(\xi)=1.00171+1.63983 \cdot 10^{-1} \xi- \\
& -1.92196 \cdot 10^{-2} \xi^{2}+1.27015 \cdot 10^{-3} \xi^{3},
\end{aligned}
$$

and at $7.71 \leq \xi<25$

$$
\begin{aligned}
& f_{\text {th.c }}(\xi)=1.38491+4.33069 \cdot 10^{-2} \xi- \\
& -2.32074 \cdot 10^{-4} \xi^{2}+1.47502 \cdot 10^{-6} \xi^{3} .
\end{aligned}
$$

For the same parameters of pipeline (diameter, wall thickness, stress intensity factor), for which
$K_{1,}, \mathrm{MPa} \sqrt{\mathrm{m}}$

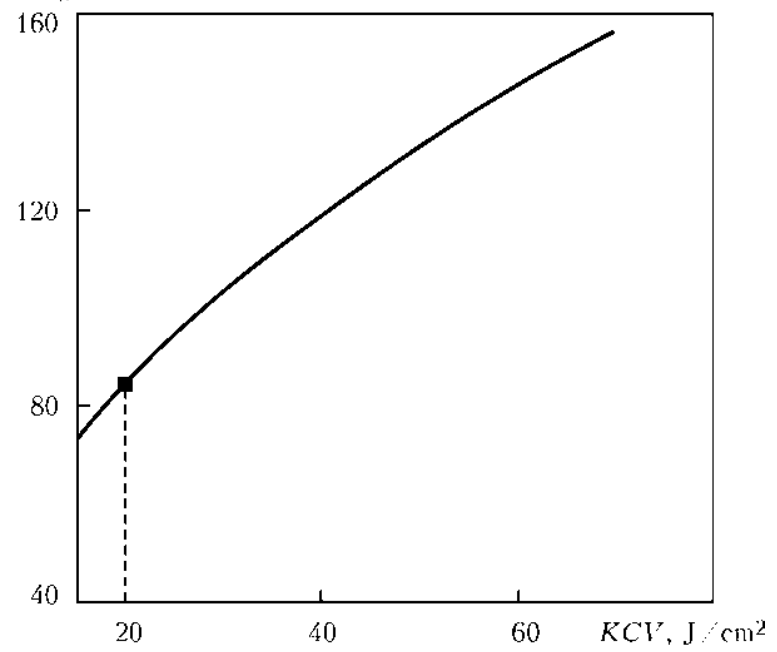

Figure 3. Dependence of critical value of stress intensity factor $K_{1 c}$ on impact toughness $K C V$ at $E=210,000 \mathrm{MPa}$ and $v=0.28$

the critical size of longitudinal crack at axial stress $\sigma_{z}=158 \mathrm{MPa}$, the critical size of hypothetic through circumferential cracks in the circumferential butt, made by FBW, amounts to $155.1 \mathrm{~mm}$.

Such established critical sizes of hypothetic through longitudinal and circumferential cracks explain a reliable (without fractures) service of main pipelines, manufactured using high-efficient FBW technology, observed during many years.

\section{Conclusions}

1. To prevent fractures connected with possible formation of technological defects in welded joints, the values of impact toughness $(K C V)$, established on the standard specimens with a sharp notch, found the wide spreading.

2 . The acceptable evaluation of impact toughness, suitable for prediction of the serviceability of welded joints, is given by $K C V$ only at the condition of proper grounds (theoretic, experimental, practical experience of service).

3. To the joints, made by FBW, at the formation of which even physical preconditions to cracks formation (molten metal is forced out from the joint zone during upsetting) do not arise, today the requirement is also set forth to provide impact toughness at the level of welded joints produced using arc methods, for which the probability of cracks formation is peculiar.

4. For the joints, produced by FBW, as a standard $K C V$ value it is most rationally to use the value, which is reliably provided at the optimal mode of welding. In the pipelines of large diameter it amounts to $20 \mathrm{~J} / \mathrm{cm}^{2}$ at $20{ }^{\circ} \mathrm{C}$ test temperature.

5. As the calculations showed, such level of impact toughness provides critical sizes of hy- 
pothetic through longitudinal and circumferential cracks in the pipeline of $1420 \mathrm{~mm}$ diameter for detection of critical sizes at working circumferential stress $\sigma_{\theta}=0.7 \sigma_{\mathrm{y}}$ and axial $\sigma_{z}=0.5 \sigma_{\theta}$. The length of longitudinal crack amounts to 42.84 and circumferential one is $155.1 \mathrm{~mm}$.

6 . The results of calculation allow meaningfully changing the attitude to the selection of $K C V$ value for the joints, made by $\mathrm{FBW}$, which will facilitate the wider application of the advanced high-efficient technology.

1. Nickols, R.U., Cowen, A. (1977) Selection of material and problems of design of large steel structures taking into account the strength of material to brittle fracture. In: Fracture. Vol. 5: Design of structures on brittle strength, 210-258. Moscow: Mashinostroenie.

2. Anuchkin, M.P., Goritsky, V.N., Miroshnichenko, B.I. (1986) Pipes for main pipelines. Moscow: Nedra.

3. Polyansky, R.P., Pasternak, V.I. (1979) Pipes for oil and gas industry abroad. Moscow: Nedra.

4. (1985) Steels for gas pipeline pipes and fittings: Proc. of Conf. Moscow: Metallurgiya.

5. GOST 25.506-85: Determination of characteristics of crack resistance (fracture toughness) under static loading. Introd. 01.01.86.

6. Girenko, V.S., Dyadin, V.P. (1985) Relation between impact toughness and fracture mechanics criteria $\delta_{1 c}$ and $K_{1 c}$ of structural steels and their welded joints. Avtomatich. Svarka, 9, 13-20.

7. Kuchuk-Yatsenko, S.I. (1992) Flash butt welding. Kiev: Naukova Dumka.

8. Kuchuk-Yatsenko, S.I., Kirian, V.I., Kazymov, B.I. et al. (2006) Methodology for control of fitness for purpose of flash butt welded joints in pipelines. The Paton Welding J., 10, 2-6.
9. Shcherbinsky, V.G., Alyokhin, N.P. (2000) Ultrasonic testing of welded joints. Moscow: N.E. Bauman MGTU.

10. GOST 7512-82: Non-destructive testing, welded joints, radiographic method. Introd. 01.01.98.

11. Kuchuk-Yatsenko, S.I., Kazymov, B.I., Radko, V.P. (1996) Complex testing of joints produced by automatic flash butt welding. Tekhn. Diagnostika $i \mathrm{Ne}-$ razrush. Kontrol, 4, 46-50.

12. Kuchuk-Yatsenko, S.I., Kazymov, B.I., Zagadarchuk, V.F. et al. (1984) Formation of «dead spots» in resistance butt welded joints. Avtomatich. Svarka, 11, 23-26.

13. (1999) API standard 1104: Welding of pipelines and related facilities ASME boiler and pressure vessel. $19 \mathrm{ed}$

14. SP 105-34-96: Fulfillment of welding jobs and testing of welded joints. Introd. 01.10.96.

15. Trufyakov, V.I., Mazur, V.G., Zhemchuzhnikov, G.V. et al. (1987) Influence of some defects on strength of butt joints produced by resistance welding. Avtomatich. Svarka, 2, 7-9.

16. Finkel, V.M., Elesina, O.P., Fedorov, V.A. et al. (1971) Elastic stresses around nonmetallic inclusions. Metallovedenie i Term. Obrab. Metallov, 7, 55-61.

17. Fridman, Ya.B. (1974) Mechanical properties of metals. Moscow: Mashinostroenie.

18. Kuchuk-Yatsenko, S.I., Kirian, V.I., Kazymov, B.I et al. (2008) Peculiarities of impact toughness tests of automatic flash butt welded joints on pipes. The Paton Welding J., 10, 5-10.

19. Osadchuk, V.A. (1980) On criterion of propagation of longitudinal and transverse cracks in closed cylindrical shells. Izvestiya AN SSSR. Mekhanika Tv. Tela, 4, 151-159.

20. Borodavkin, P.P., Sinyukov, A.M. (1984) Strength of main pipelines. Moscow: Nedra.

Received 13.11.2014 